\title{
Synthesis and Characterization of Fluorene-Based Polymers Having Azine Unit for Blue Light Emission
}

\author{
Zhong Min Geng ${ }^{1,2}$, Masashi Kijima ${ }^{2,3, a, *}$ \\ ${ }^{1}$ Institute of Materials Science, Graduate School of Pure and Applied Sciences, University of \\ Tsukuba, 1-1-1 Tennodai, Tsukuba, Ibaraki 305-8573, Japan \\ ${ }^{2}$ Tsukuba Research Center for Interdisciplinary Materials Science, University of Tsukuba, 1-1-1 \\ Tennodai, Tsukuba, Ibaraki 305-8573, Japan \\ ${ }^{3}$ Division of Materials Science, Faculty of Pure and Applied Sciences, University of Tsukuba, 1-1-1 \\ Tennodai, Tsukuba, Ibaraki 305-8573, Japan \\ *Email: kijima@ims.tsukuba.ac.jp
}

Keywords: Tetrazine, Triazine, Donor-acceptor

\begin{abstract}
Two types of donor-acceptor copolymers were designed and synthesized by combination of an electron donor unit of fluorene sequences and an electron acceptor azine unit such as 1,2,4,5-tetrazine and 1,3,5-triazine. They were well soluble in common organic solvents with the number average molecular weight $\left(M_{\mathrm{n}}\right)$ of 7.0 and $14.5 \mathrm{~kg} \mathrm{~mol}^{-1}$, respectively, and have good thermal stability showing about at $360{ }^{\circ} \mathrm{C}$ with $5 \mathrm{wt} \%$ loss in TGA. Two copolymers exhibited intense blue photoluminescence with emission peak maxima at 437 and $421 \mathrm{~nm}$ in $\mathrm{CHCl}_{3}$, and 451 and $422 \mathrm{~nm}$ in the film state, respectively. These polymers exhibited good fluorescence quantum efficiencies in $\mathrm{CHCl}_{3}\left(\phi_{\mathrm{fl}}=0.63,0.97\right)$. Energy levels of the highest occupied molecular orbital and lowest unoccupied molecular orbital energy levels estimated by cyclic voltammetry were to be $-5.83,-6.0 \mathrm{eV}$ and $-2.85,-2.88 \mathrm{eV}$, respectively.
\end{abstract}

\section{Introduction}

Conjugated polymers have gained large interest through various organic electronic applications such as organic light emitting diodes (OLEDs) [1-3], light emitting electrochemical cells (LECs) [4-6], organic solar cells [7,8] and organic thin-film transistors [9]. Blue light-emitting materials are of great significance for their unique applications in flat-panel displays and high-density information storage. Especially in full-color displays, the short-wavelength emission can serve as an excitation source for emission over the whole visible range [10]. Therefore, development of high-efficiency blue emitting materials is important. However, to develop stable pure blue polymeric emitters with their color coordinates in the Commission Internationale de L'Eclairage (CIE) chromaticity diagram within the standard blue (CIE: $x<0.15 ; y<0.1$ ) are still rare since the large energy bandgap $\left(E_{\mathrm{g}}\right)$ of these materials makes the achievement of high efficiency and a good charge balance difficult [11]. In this framework, the rational design of p-type conjugated polymers by incorporating electron-withdrawing groups, such as azine unit, seems to be a straightforward strategy to tune carrier injection and transporting properties of known materials [12]. A new donor-acceptor (D-A) system has been designed, which is expected to lower both the energy level of the highest occupied molecular orbital $\left(E_{\mathrm{HOMO}}\right)$ and energy level of the lowest unoccupied molecular orbital $\left(E_{\mathrm{LUMO}}\right)$, giving rise to a series of intriguing properties such as improved resistance to oxidation, facilitated electron injection, and ambipolar characteristics, which could simplify device fabrication and operation.

In this paper, the synthesis, characterization and photoluminescence properties of fluorene-based polymers, PF-tetrAz or PF-triAz, shown in Fig.1 were investigated. Herein, the 
fluorene sequences were selected as D for the reason of good thermal and electrochemical stability, high fluorescence yield and facile chemical functionalization [13,14], while 1,2,4,5-tetrazine (tetrAz) and 1,3,5-triazine (triAz) were chosen as A for their electron deficiency [12].

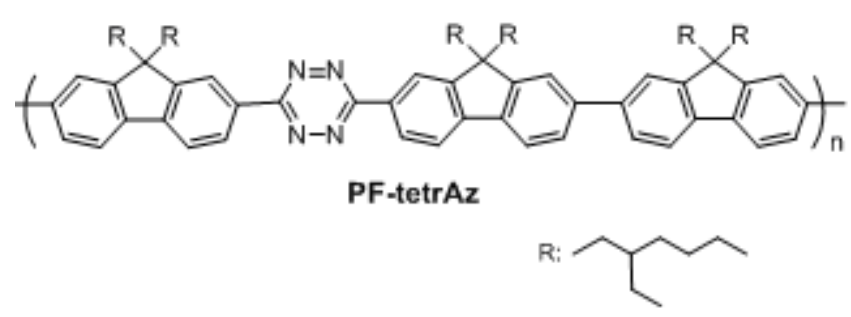

Fig. 1. Chemical structures of PF-tetrAz and PF-triAz
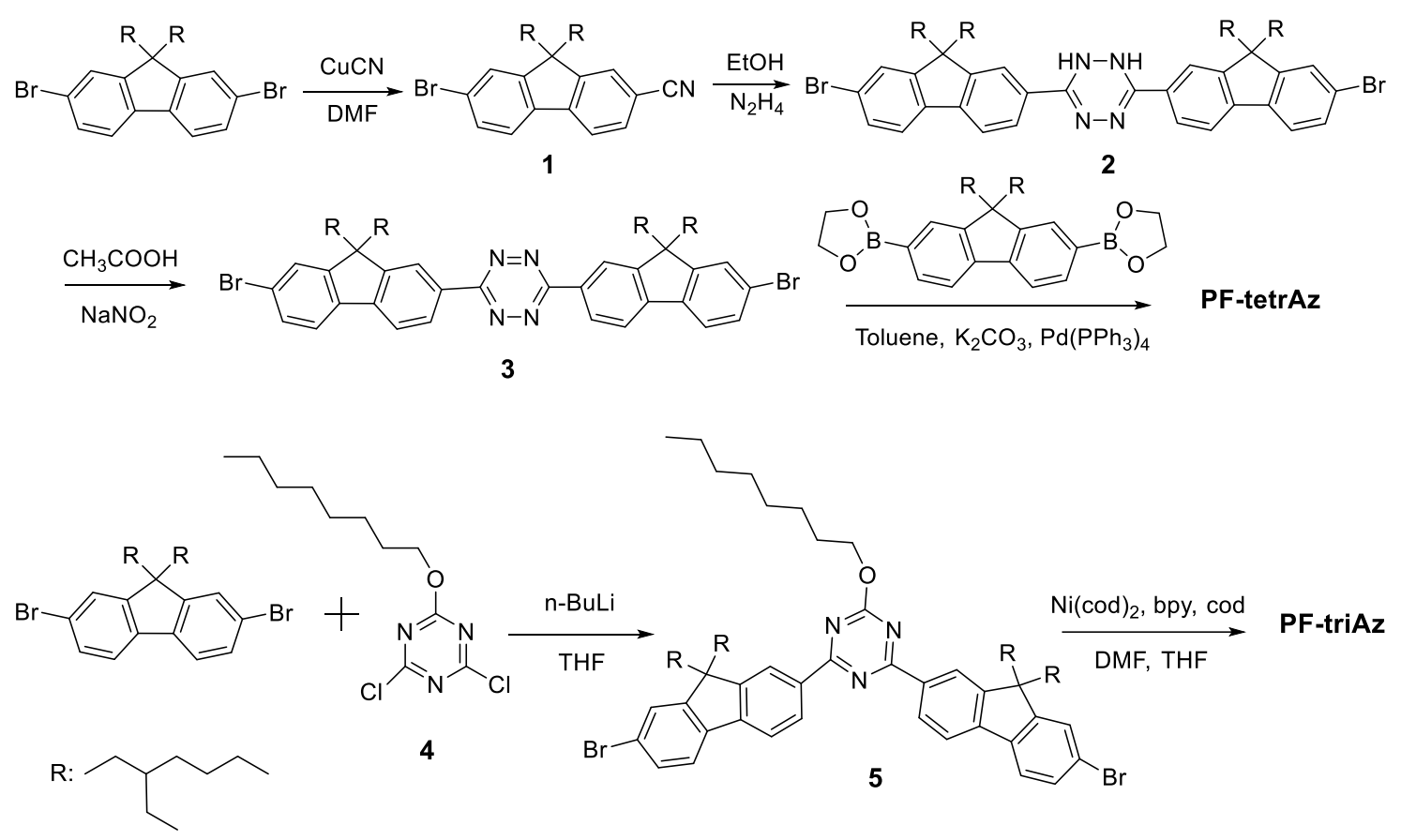

Scheme 1. Synthetic routes of PF-tetrAz and PF-triAz.

\section{Experimental}

\subsection{Materials}

Two polymers (PF-tetrAz and PF-triAz) were synthesized according to the Scheme 1. 7-Bromo-9,9-bis(2-ethylhexyl)-9H-fluorene-2-carbonitrile 1, 2,4-dichloro-6-(octyloxy)-1,3,5triazine 4 and 2,2'-(9,9-bis(2-ethylhexyl)-9H-fluorene-2,7-diyl)bis- 1,3,2-dioxaborolane were synthesized according to the procedures reported previously [15-17]. Reagents and solvents were purchased from Kanto Chemical, Tokyo Chemical Industry, Aldrich and Nacalai Tesque Inc. Dimethylformamide (DMF) distilled after drying with $\mathrm{CaH}_{2}$ was stored under an argon atmosphere. Tetrahydrofuran (THF) distilled after drying with sodium was stored under an argon atmosphere. The other solvents and all commercially available reagents were used without further purification.

3,6-Bis(7-bromo-9,9-bis(2-ethylhexyl)-9H-fluorene-2-yl)-1,2-dihydro[1,2,4,5] tetrazine (2). To suspension of $1(0.2 \mathrm{~g}, 0.41 \mathrm{mmol})$ in $1 \mathrm{~mL}$ ethanol was quickly added hydrazine $(0.019 \mathrm{~mL}, 0.615$ mmol) and sulfur $(0.008 \mathrm{~g}, 0.25 \mathrm{mmol})$. The mixture was refluxed for $3 \mathrm{~h}$ with stirring and then 
placed in an ice bath for further solidification. The orange precipitate was collected by filtration and washed with cold ethanol $(2 \times 10 \mathrm{~mL})$ to give a crude dihydrotetrazine, which was used in the next step without further purification.

3,6-Bis(7-bromo-9,9-bis(2-ethylhexyl)-9H-fluorene-2-yl)-[1,2,4,5]tetrazine (3). The orange solid of 2 was dissolved in acetic acid $(1 \mathrm{~mL})$ at room temperature with stirring. $\mathrm{NaNO}_{2}(0.028 \mathrm{~g}, 0.41$ mmol) was added to the solution at $0{ }^{\circ} \mathrm{C}$. The purple precipitate signified the completion of the reaction was collected by filtration and washed with methanol $(2 \times 5 \mathrm{~mL})$ to give a dark purple solid (0.176 g, 84.6\%). ${ }^{1} \mathrm{H}$ NMR (400 MHz, $\left.\mathrm{CDCl}_{3}\right) \delta[\mathrm{ppm}]: 8.08(\mathrm{~s}, 2 \mathrm{H}), 8.01(\mathrm{~d}, \mathrm{~J}=8.25 \mathrm{~Hz} 2 \mathrm{H})$, $7.78(\mathrm{~d}, \mathrm{~J}=8.25 \mathrm{~Hz} 2 \mathrm{H}), 7.62(\mathrm{~d}, \mathrm{~J}=8.25 \mathrm{~Hz} 2 \mathrm{H}), 7.56(\mathrm{~s}, 2 \mathrm{H}), 7.50(\mathrm{~d}, \mathrm{~J}=8.25 \mathrm{~Hz} 2 \mathrm{H}), 2.12-2.03$ $(\mathrm{m}, 8 \mathrm{H}), 1.28-1.25(\mathrm{~m}, 4 \mathrm{H}), 0.91-0.77(\mathrm{~m}, 32 \mathrm{H}), 0.56-0.50(\mathrm{~m}, 24 \mathrm{H}) .{ }^{13} \mathrm{C} \mathrm{NMR}\left(100 \mathrm{MHz}, \mathrm{CDCl}_{3}\right)$ $\delta[\mathrm{ppm}]: 177.3,157.7,153.3,144.7,138.2,130.5,130.4,128.4,127.6,127.5,122.0,120.3,55.5$, $44.2,34.7,33.6,28.0,27.1,22.6,14.1,10.3$.

2-Octyloxy-4,6-bis(7-bromo-9,9-bis(2-ethylhexyl)-9H-fluorene-2-yl)-1,3,5-triazine(5).

9,9-Bis(2-ethylhexyl)-2,7-dibromofluorene $(0.44 \mathrm{~g}, 0.80 \mathrm{mmol})$ was dissolved in dry THF $(4 \mathrm{~mL})$ and cooled to $-78{ }^{\circ} \mathrm{C}$ under nitrogen atmosphere, in which $1.6 \mathrm{M} \mathrm{n}-\mathrm{BuLi} / \mathrm{hexane}$ solution $(0.56 \mathrm{~mL}$, $0.9 \mathrm{mmol})$ was added dropwise with stirring. The mixture was kept at $-78{ }^{\circ} \mathrm{C}$ for $1 \mathrm{~h}$ and $4(0.11 \mathrm{~g}$, $0.4 \mathrm{mmol}$ ) was slowly added. The reaction mixture was stirred for another $15 \mathrm{~min}$ at $-78{ }^{\circ} \mathrm{C}$. Afterward, the solution was allowed to warm up to room temperature and stirred for $24 \mathrm{~h}$, and quenched with addition of water. After extraction with $\mathrm{CH}_{2} \mathrm{Cl}_{2}$, drying over $\mathrm{MgSO}_{4}$ and the solvent evaporation, the crude product was purified by column chromatography (silica gel, $\mathrm{CH}_{2} \mathrm{Cl}_{2} /$ hexane, $1: 2$, as eluent) to afford a yellow oil $(0.088 \mathrm{~g}, 51 \%) .{ }^{1} \mathrm{H} \mathrm{NMR}\left(400 \mathrm{MHz}, \mathrm{CDCl}_{3}\right) \delta[\mathrm{ppm}]: 8.66(\mathrm{~s}$, 4H), $7.82(\mathrm{~d}, \mathrm{~J}=7.78 \mathrm{~Hz} 2 \mathrm{H}), 7.65(\mathrm{~d}, \mathrm{~J}=7,78 \mathrm{~Hz} 2 \mathrm{H}), 7.58(\mathrm{~d}, \mathrm{~J}=7.78 \mathrm{~Hz} 2 \mathrm{H}), 7.51$ (d, J= $7.79 \mathrm{~Hz}$ 2H), $4.66(\mathrm{~m}, 2 \mathrm{H}), 2.13-1.90(\mathrm{~m}, 10 \mathrm{H}), 1.32-0.82(\mathrm{~m}, 42 \mathrm{H}), 0.58-0.52(\mathrm{~m}, 27 \mathrm{H}) .{ }^{13} \mathrm{C}$ NMR $(100$ $\left.\mathrm{MHz}, \mathrm{CDCl}_{3}\right) \delta[\mathrm{ppm}]: 173.5,170.3,153.9,150.4,144 . .5,139.4,134.5,130.1,128.4,127.5,124.6$, $121.7,121.6,119.6,68.1,55.3,44.3,34.7,33.5,31.8,29.4,29.1,28.8,28.1,27.1,26.0,22.7,22.6$, $14.1,14.0,10.4$.

$\operatorname{Poly}\left[\left(9,9,9^{\prime}, 9^{\prime}, 9^{\prime \prime}, 9^{\prime \prime}\right.\right.$-hexaxis(2-ethylhexyl) [2,2':7',2"'-ter-9H-fluorene]-7, 7"-diyl)-([1,2,4,5]tetrazine -3,6-diyl)] (PF-tetrAz). A mixture of 2,2'-(9,9-bis(2-ethylhexyl)-9H-fluorene-2,7diyl)bis-1,3,2-dioxaborolane $(0.037 \mathrm{~g}, \quad 0.07 \mathrm{mmol})$, tetrakis(triphenylphosphine) palladium $\left(\mathrm{Pd}\left(\mathrm{PPh}_{3}\right)_{4}, 4.1 \mathrm{mg}\right)$, aqueous $\mathrm{K}_{2} \mathrm{CO}_{3}(2 \mathrm{M}, 0.7 \mathrm{~mL})$ and $3(0.071 \mathrm{~g}, 0.07 \mathrm{mmol})$ in toluene $(1.0 \mathrm{~mL})$ was refluxed with vigorous stirring for three days under argon atmosphere. After the reaction solution was cooled to room temperature, the resultant polymer was precipitated from methanol/HCl aq, and reprecipitated from methanol/ $\mathrm{NH}_{3}$ aq and from methanol, respectively. The precipitate was successively extracted with acetone, hexane and $\mathrm{CHCl}_{3}$ by Soxhlet extraction. The $\mathrm{CHCl}_{3}$ extract was again precipitated from methanol. PF-tetr $\mathbf{A z}$ was obtained as an orange solid $(0.077 \mathrm{~g}, 80 \%) .{ }^{1} \mathrm{H}$ NMR $\left(400 \mathrm{MHz}, \mathrm{CDCl}_{3}\right) \delta[\mathrm{ppm}]: 8.12(\mathrm{br}, 4 \mathrm{H}), 7.82(\mathrm{br}, 4 \mathrm{H}), 7.70-7.59(\mathrm{~m}$, $8 \mathrm{H}), 7.49$ (br, 1H), 7.36 (br, 1H), 2.17-2.0 (m, 12H), 1.11-0.80 (m, 54H), 0.63-0.57 (m, 36H). $\mathrm{C}_{89} \mathrm{H}_{122} \mathrm{~N}_{4}$ (1246.89): Calcd. C 85.66, H 9.85, N 4.49; Found. C 83.48, H 9.33, N 4.38.

\section{Poly[(9,9,9',9'-tetrakis(2-ethylhexyl)-9H-fluorene-7,7'-diyl)-92-octyloxy-1,3,5-triazine-4,6-diyl)]}

(PF-triAz). Under an argon atmosphere, a solution of bis $\left(1,5\right.$-cycloocta- -diene)nickel $(0)\left(\mathrm{Ni}(\operatorname{cod})_{2}\right)$ (0.110 g, $0.40 \mathrm{mmol}), 2,2^{\prime}$-bipyridine (bpy) $(0.070 \mathrm{~g}, 0.448 \mathrm{mmol})$ and 1,5 -cyclooctadiene (cod) $(0.10 \mathrm{~g}, 0.92 \mathrm{mmol})$ in DMF $(1 \mathrm{~mL})$ was heated for $30 \mathrm{~min}$ at $80{ }^{\circ} \mathrm{C}$. To the DMF solution was 
added 5 (0.083 g, $0.184 \mathrm{mmol})$ dissolved in THF $(1 \mathrm{~mL})$ under argon. The reaction solution was heated for 3 days at $80^{\circ} \mathrm{C}$. After the reaction solution was cooled to room temperature, the resultant polymer was precipitated from methanol/ $\mathrm{HCl}$ aq, and reprecipitated from methanol $/ \mathrm{NH}_{3}$ aq and from methanol, respectively. The precipitate was successively extracted with acetone, hexane and $\mathrm{CHCl}_{3}$ by Soxhlet extraction. The $\mathrm{CHCl}_{3}$ extract was again precipitated from methanol. PF-triAz was obtained as a white solid $(0.060 \mathrm{~g}, 83 \%) .{ }^{1} \mathrm{H}$ NMR $\left(400 \mathrm{MHz}, \mathrm{CDCl}_{3}\right) \delta[\mathrm{ppm}]: 8.73(\mathrm{~s}, 4 \mathrm{H})$, $7.90(\mathrm{~s}, 4 \mathrm{H}), 7.70(\mathrm{~s}, 4 \mathrm{H}), 4.69(\mathrm{~s}, 2 \mathrm{H}), 2.17(\mathrm{~s}, 8 \mathrm{H}), 1.97(\mathrm{~m}, 2 \mathrm{H}), 0.93-0.87(\mathrm{~m}, 42 \mathrm{H}), 0.68-0.60$ (m, 27H). $\mathrm{C}_{71} \mathrm{H}_{103} \mathrm{~N}_{3} \mathrm{O}$ (1013.70): Calcd. C 84.05, H 10.23, N 4.14; Found. C 82.23, H 9.66, N 3.84.

\subsection{General Method and Instrumentation}

All synthetic manipulations were performed by a standard technique using a Schlenk tube under an argon atmosphere. Column chromatography was performed using a silica gel (Kanto Chem., 60 $\mathrm{N}, 63-120 \mathrm{~mm}$ ). Nuclear magnetic resonance (NMR) spectra were recorded on a JEOL JNM-ECS 400 spectrometer. ${ }^{1} \mathrm{H}$ and ${ }^{13} \mathrm{C}$ chemical shifts are given in units of $\delta(\mathrm{ppm})$ relative to $\delta$ (TMS) $=$ 0.00 and $\delta\left(\mathrm{CDCl}_{3}\right)=77.0 \mathrm{ppm}$, respectively. Photoabsorption in the range of ultraviolet-visible (UV-vis) and photoluminescence (PL) measurements of the polymer samples in $\mathrm{CHCl}_{3}$ and in a form of a thin film coating on a quartz glass were performed using a Shimadzu UV-1800 spectrophotometer and an F-4500 fluorescence spectrophotometer (Hitachi). The fluorescence quantum yield in $\mathrm{CHCl}_{3}$ were relative to 9,10 -diphenylanthracene in cyclohexane $\left(\phi_{\mathrm{fl}}=0.90\right)$ as a standard. The number-average molecular weight $\left(M_{\mathrm{n}}\right)$ and the weight-average molecular weight $\left(M_{\mathrm{w}}\right)$ of the polymers were estimated by gel permeation chromatography (GPC) system (Shimadzu, LCsolution) using polystyrene standards with $\mathrm{CHCl}_{3}$ as an eluent. Cyclic voltammetry (CV) of polymers in thin film on a Pt disk was performed at a scan rate of $50 \mathrm{mV} / \mathrm{s}$ in acetonitrile containing $0.1 \mathrm{M} \mathrm{Et}_{4} \mathrm{NBF}_{4}$ at room temperature under Ar using a saturated calomel electrode (SCE) as the reference and a platinum wire as the counter electrode. The electrochemical data (vs SCE) obtained by cyclic voltammetry were made a correction with the redox potential $(4.8 \mathrm{eV})$ of ferrocene/ferricinium [18, 19]. Elemental analyses were carried out with a Perkin-Elmer type 2400 apparatus. Thermal gravimetric analysis (TGA) and differential thermal analysis (DTA) were carried out by an Extra 6000 TG/DTA (Seiko) analyzer at a heating rate of $10{ }^{\circ} \mathrm{C} \mathrm{min}^{-1}$ in an argon atmosphere.

\section{Results and Discussion}

\subsection{Synthesis.}

The general synthetic routes toward the monomer and polymer PF-tetrAz and PF-triAz are outlined in Scheme 1. Dihydrotetrazine intermediate 2, cyclized of $\mathbf{1}$ with anhydrous hydrazine by heating, was oxidized instantly into the fully aromatic tetrazine $\mathbf{3}$ for its instability. Tetrazine $\mathbf{3}$ was polymerized by Suzuki coupling reaction with 2,2'-(9,9-bis(2-ethylhexyl)-9H-fluorene-2,7diyl)bis-1,3,2-dioxaborolane to give PF-tetrAz. 2,7-Dibromo-9,9-bis(2-ethylhexyl)fluorene reacted with $\mathbf{4}$ to give $\mathbf{5}$. Homopolymerization of $\mathbf{5}$ by the Yamamoto reaction [20] afforded PF-triAz as a white solid. All the copolymers had good solubility in common organic solvents such as $\mathrm{CHCl}_{3}$, chlorobenzene, and $o$-dichlorobenzene. The polymers were identified by NMR and elemental analyses. The GPC results were summarized in Table 1. The $M_{\mathrm{n}}$ of PF-tetrAz and PF-triAz were 7.0 and $14.5 \mathrm{~kg} / \mathrm{mol}$, respectively. TGA results are shown in Fig. 2. Observed temperatures for 5wt \% loss were 363 and $387{ }^{\circ} \mathrm{C}$, respectively, which suggest that both have good thermal stability comparable to polyfluorenes [21]. 
Table 1. GPC and TGA results of the polymers.

\begin{tabular}{ccccc}
\hline Polymer & $\begin{array}{c}M_{\mathrm{n}} \\
\left(\mathrm{kg} \cdot \mathrm{mol}^{-1}\right)\end{array}$ & $\begin{array}{c}M_{\mathrm{w}} \\
\left(\mathrm{kg} \cdot \mathrm{mol}^{-1}\right)\end{array}$ & $M_{\mathrm{w}} / M_{\mathrm{n}}$ & $T_{\mathrm{d}}\left({ }^{\circ} \mathrm{C}\right)^{\mathrm{a}}$ \\
\hline PF-tetrAz & 7.0 & 7.6 & 1.08 & 363 \\
\hline PF-triAz & 14.5 & 21.9 & 1.52 & 387 \\
\hline
\end{tabular}

${ }^{\text {a }}$ Temperature of $5 \%$ weight loss determined by TGA under an argon atmosphere.

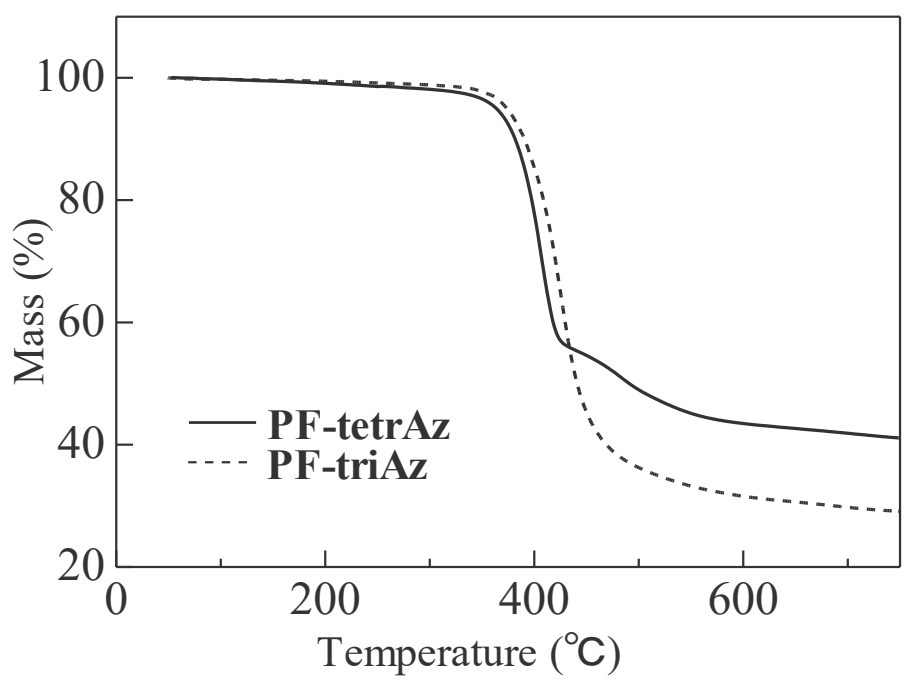

Fig. 2. Thermal gravimetric analysis (TGA) curves of the polymers.

\subsection{Optical properties.}

The photophysical properties of dilute solution and thin films of all the polymers were investigated with UV-vis and PL, and the results are shown in Fig. 3. The UV-vis absorption and the emission spectra data for polymer were summarized in Table 2.
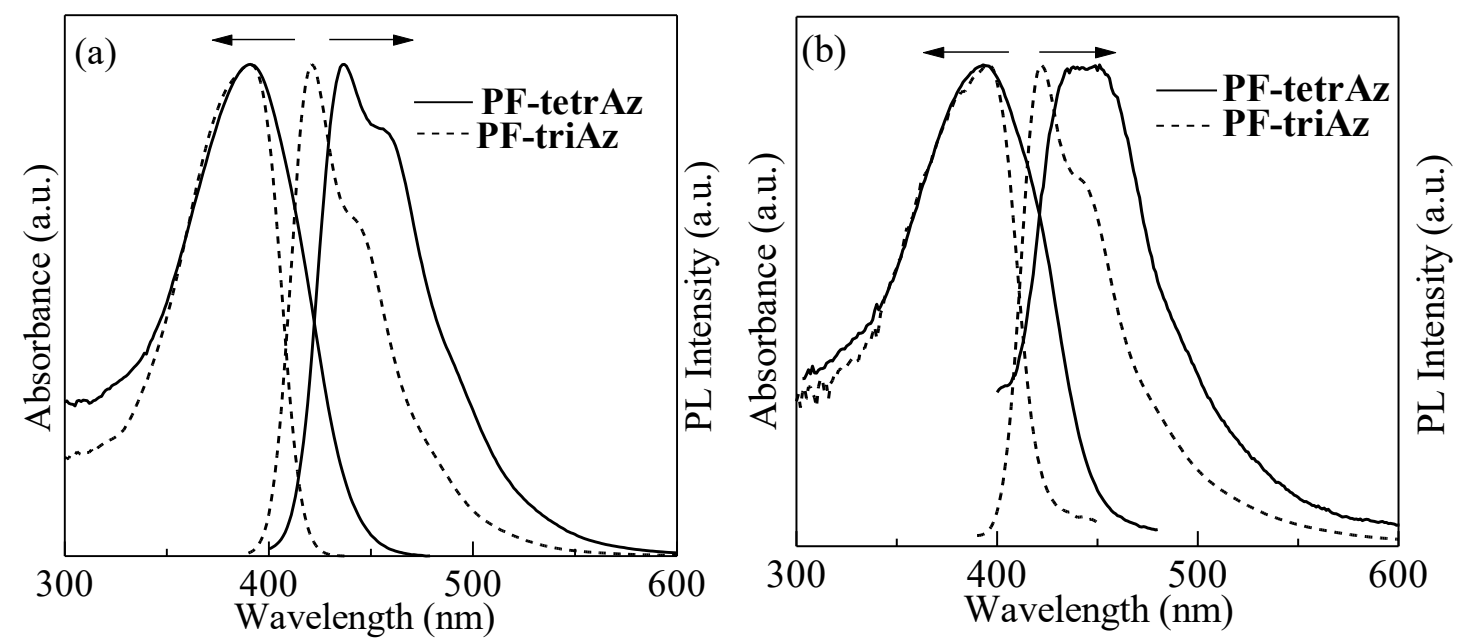

Fig. 3. UV-vis absorption spectra and photoluminescence (PL) of the polymers in $\mathrm{CHCl}_{3}$ (a) and film state (b). 
Table 2. Optical properties, energy gaps and levels of the polymers.

\begin{tabular}{|c|c|c|c|c|c|c|c|c|c|}
\hline \multirow{2}{*}{ Polymer } & \multicolumn{2}{|c|}{ Abs. $\lambda_{\max }(\mathrm{nm})$} & \multicolumn{2}{|c|}{$\operatorname{Em} . \lambda_{\max }(\mathrm{nm})$} & \multirow{2}{*}{$\phi_{\mathrm{fl}}$} & \multirow{2}{*}{$\begin{array}{l}E_{\mathrm{g}}{ }^{\mathrm{opt}} \\
(\mathrm{eV})\end{array}$} & \multirow{2}{*}{$\begin{array}{c}E_{\mathrm{HOMO}} \\
(\mathrm{eV})\end{array}$} & \multirow{2}{*}{$\begin{array}{c}E_{\mathrm{LUMO}} \\
(\mathrm{eV})\end{array}$} & \multirow{2}{*}{$\begin{array}{l}E_{\mathrm{g}}^{\mathrm{ec}} \\
(\mathrm{eV})\end{array}$} \\
\hline & $\mathrm{CHCl}_{3}$ & film & $\mathrm{CHCl}_{3}$ & film & & & & & \\
\hline PF-tetrAz & 390 & 393 & 437 & 451 & 0.63 & 2.80 & -5.83 & -2.85 & 2.96 \\
\hline PF-triAz & 394 & 395 & 421 & 422 & 0.97 & 2.98 & -6.0 & -2.88 & 3.12 \\
\hline
\end{tabular}

Absorption and PL spectra of PF-tetrAz and PF-triAz in $\mathrm{CHCl}_{3}$ are shown in Fig. 3a. The absorption maxima in wavelength $\left(\lambda_{\max }\right)$ at $390 \mathrm{~nm}$ for PF-tetrAz and $394 \mathrm{~nm}$ for PF-triAz are due to $\pi-\pi^{*}$ transition of the conjugated main chains. The absorption $\lambda_{\max }$ of PF-triAz is in long wavelengths compared with that of PF-tetrAz, which indicates that $\pi$-conjugation of PF-triAz is longer than that of PF-tetrAz. The emission peaks in solution were observed at $437 \mathrm{~nm}$ for PF-tetrAz and $421 \mathrm{~nm}$ for PF-triAz. Stokes shifts of PF-triAz in the solution was $27 \mathrm{~nm}$, which was much smaller than that of PF-tetrAz $(47 \mathrm{~nm})$. These small Stokes shifts also support PF-triAz having rigid and regular conformation, which enabled utilization of absorbed energy to PL efficiently.

The absorption and PL spectra of PF-tetrAz and PF-triAz in thin solid film state are shown in Fig. 3b. Compared with absorption spectra in solution, the absorption of PF-tetrAz and PF-triAz is slightly broaden and red shift compared with their absorption in film. The broadening and red shift of the film absorption spectra indicated that there were some aggregations or interactions of the polymer chains in the solid state. The optical band gap $\left(E_{\mathrm{g}}{ }^{\mathrm{opt}}\right)$ estimated from the onset of the absorption spectrum in the film state was $2.8 \mathrm{eV}$ for PF-tetrAz, which was smaller than that of PF-triAz (2.98 eV). Compared with PL spectra of PF-tetrAz and PF-triAz in solution, a red shift was observed in their film. The PL maxmum of PF-triAz in the film state was shorter in wavelength than that of PF-tetrAz. This can be attributed to the higher polarizability of the tetrAz group and restrained intermolecular aggregation [22].

PF-tetrAz and PF-triAz showed intense blue PL emission with CIE coordinates $(x, y=0.16$, $0.12 ; 0.16,0.07$, respectively) in the film state and good relative $\phi_{\mathrm{fl}}$ of $0.63,0.97$ in $\mathrm{CHCl}_{3}$, which suggest that PF-tetrAz and PF-triAz are considered to be good polymeric blue emitters superior to a series of polyfluorene derivatives [23].

\subsection{Electrochemical Properties.}

Electrochemical analysis of the thin-film sample of the polymers was employed to estimate $E_{\mathrm{HOMO}}$ and $E_{\mathrm{LumO}}$. The CV results of PF-tetrAz and PF-triAz are shown in Fig. 4 and the estimated values are summarized in Table 2. During the anodic scan, both of the compounds showed irreversible oxidation peaks, which are assigned to the oxidation of the fluorene units. PF-tetrAz had $E_{\text {HOMO }}$ of $-5.83 \mathrm{eV}$, which was higher about $0.17 \mathrm{eV}$ than that of PF-triAz $(-6.0 \mathrm{eV})$. This could be caused by the delocalization of the HOMO because of good planarity between the fluorene and tetrAz segments. Upon the cathodic sweep, PF-triAz exhibited quasireversible reduction waves, whereas PF-tetrAz showed weak irreversible reduction waves. The $E_{\mathrm{LUMO}}$ of PF-tetrAz $(-2.85 \mathrm{eV})$ is slightly lower than that of PF-triAz $(-2.74 \mathrm{eV})$, on account of higher electron-deficiency of tetrAz compared to triAz. The above results suggest that electronegativity of the azine unit is responsible for lowering of both $E_{\mathrm{HOMO}}$ and $E_{\mathrm{LUMO}}$ of the polymers. 


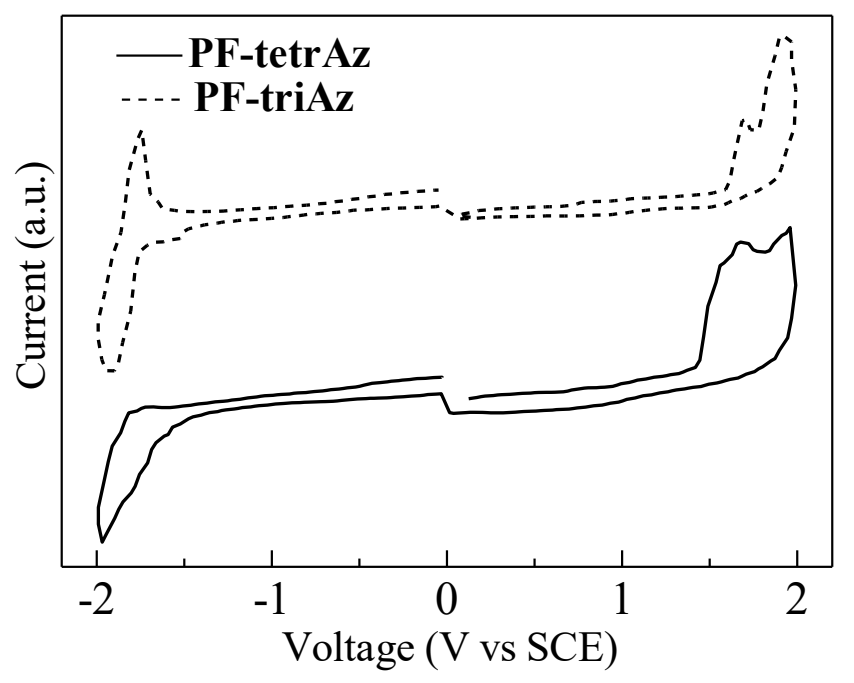

Fig. 4. Cyclic voltammograms of PF-tetrAz and PF-triAz.

Estimated from the $E_{\mathrm{HOMO}}$ and $E_{\mathrm{LUMO}}$, the $E_{\mathrm{g}}{ }^{\text {ec }}$ values of 2.96 and $3.12 \mathrm{eV}$ are obtained for PF-tetrAz and PF-triAz, respectively, which are similar to $E_{\mathrm{g}}{ }^{\text {opt }}$. These energy gaps with suitable $E_{\mathrm{HOMO}}$ and $E_{\mathrm{LUMO}}$ are good for lessening driving voltage and augmenting efficiency of OLEDs [24].

\section{Conclusion}

In summary, two efficient blue luminescence polymers PF-tetrAz and PF-triAz, have been developed by combination of the fluorene sequenes as a electron-donor and the tetrAz or $\operatorname{triAz}$ core as an electron-acceptor. These polymers were obtained in high yields, and they had a good solubility in common organic solvents and a good thermal stability. In the $\mathrm{CHCl}_{3}$ solution, they showed similar electronic properties of absorption and emission, the values of $\lambda_{\max }(\mathrm{abs})$ and $\lambda_{\max }(\mathrm{em})$ of each polymer were about 390 and $430 \mathrm{~nm}$, respectively. In the state of the thin films, PF-triAz showed deep blue fluorescence with the values of $\lambda_{\max }(\mathrm{em})$ at $422 \mathrm{~nm}$ and emission indicatable by CIE coordinates $(0.16,0.07)$ in the film state. PF-tetrAz and PF-triAz showed acceptable $E_{\text {Номо }}(-5.83,-6.0 \mathrm{eV})$ for hole transport and proper $E_{\mathrm{g}}(2.96,3.12 \mathrm{eV})$ for blue emission. According to these results, these D-A copolymers have a great potential to be applied in OLEDs and LECs as the blue-light emitting materials.

\section{References}

[1] S. Beaupré, M. Leclerc, Adv. Funct. Mater. 12 (2002) 192-196.

[2] U. Mitschke, P. Bäuerle, J.Mater. Chem. 10 (2000) 1471-1507.

[3] D. Y. Kim, H.N. Cho, C.Y. Kim, Prog. Polym. Sci. 25 (2000) 1089-1139.

[4] A. Pertegás, D. Tordera, J.J. Serrano-Pérez, E. Ortí, H. J. Bolink, J. Am. Chem. Soc. 135 (2013) 18008-18011.

[5] Z. Yu, L. Li, H. Gao, Q. Pei, Sci. China-Chem. 56 (2013) 1075-1086.

[6] Q. Pei, G, Yu, C, Zhang, Y, Yang, A, Heeger, J. Science. 269 (1995) 1086-1088.

[7] E. Bundgaard, F. C. Krebs, Sol. Energy Mater. Sol. Cells. 91 (2007) 954-985.

[8] S. Günes, H. Neugebauer, N. S. Sariciftci, Chem. Rev. 107 (2007) 1324-1338.

[9] M. M. Durban, P. D. Kazarinoff, C. K. Luscombe, Macromolecules. 43 (2010) 6348-6352.

[10] J. Ye, Z. Chen, M.K. Fung, C. Zheng, X. Ou, Y. Yuan, C.S. Lee, Chem. Mater. 25 (2013) 2630-2637. 
[11] T. Horii, T, Shinnai, K, Tsuchiya, T, Mori, M. Kijima, J. Polym. Sci. Polym. Chem. 50 (2012) 4557-4562.

[12] S. Ren, D. Zeng, H. Zhong, Y. Wang, S. Qian, Q. Fang, J. Phys. Chem. B. 114 (2010) 10374-10383.

[13] R.F. He, S.J. Hu, J. Liu, L. Yu, B. Zhang, N. Li, W. Yang, H.B. Wu, J.B. Peng, J. Mater. Chem. 22 (2012) 3440-3446.

[14] J. Ye, Z. Chen, M.K. Fung, C. Zheng, X. Ou, X. Zhang, Y. Yuan, C.S. Lee, Chem. Mater. 25 (2013) 2630-2637.

[15] S. Yrjölä, T. Kalliokoski, T. Laitinen, A. Poso, T. Parkkari, T. Nevalainen, Eur. J. Pharm. Sci. 2013, 48, 9-20.

[16] T.C. Lin, Y.H. Lee, B.R. Huang, C.L. Hu, Y.K. Li, Tetrahedron. 68 (2012) 4935-4949.

[17] Y. Li, J. Ding, M. Day, Y. Tao, J. Lu, M. D'iorio, Chem. Mater. 16 (2004) 2165-2173.

[18] J. Pommerehne, H. Vestweber, W. Guss, R.F. Mahrt, H. Bässler, M. Porsch, J. Daub, Adv. Mater. 7 (1995) 551-554.

[19] A. K. Agrawal, S. A. Jenekhe, Chem. Mater. 8 (1996) 579-589.

[20] T. Yamamoto, A. Morita, Y. Muyazaki, T. Maruyama, H. Wakayama, Z. H. Zhou, Y. Nakamura, T. Kanbara, S. Sasaki, K. Kubota, Macromolecules. 25 (1992) 1214-1223.

[21] D. Marsitzky, R. Vestberg, P. Blainey, B. T. Tang, C. J. Hawker, K. F. Carter, J. Am. Chem. Soc. 123 (2001) 6965-6972.

[22] H. Alyar, M. Bahat, Z. Kantarc1, E. Kasap, Comput. Theor. Chem. 977 (2011) 22-28.

[23] T. Horii, T. Shinnai, K. Tsuchiya, T. Mori, M. Kijima, J. Polym. Sci. Part A: Polym. Chem. 50 (2012) 4557-4562.

[24] Z. Q. Gao, M. Luo, X.H. Sun, H.L. Tam, M.S. Wong, B.X. Mi, P.F. Xia, K.W. Cheah, C.H. Chen, Adv. Mater. 21 (2009) 688-692. 